\title{
DIÁLOGOS POSSÍVEIS ENTRE OS PRESSUPOSTOS DO CÍRCULO DE BAKHTIN E OS ESTUDOS DA LINGUÍSTICA APLICADA
}

\author{
POSSIBLE DIALOGUES BETWEEN THE ASSUMPTIONS OF THE BAKHTIN \\ CIRCLE AND APPLIED LINGUISTIC STUDIES
}

DOI 10.20873/uft2179-3948.2021v12n1p309-323

Antônia Albaneide de Sousa
Ângela Francine Fuza
Án

Resumo. Este artigo, de escopo bibliográfico, objetiva discutir, epistemológica e teoricamente, as possíveis relações entre as teorias do Círculo de Bakhtin (VOLOCHÍNOV, 1992[1929]; BAKHTIN, 1997 [1929/1963]; BAKHTIN, 2003[1979]) e as da Linguística Aplicada (CELANI, 1992; KLEIMAN, 1998; MOITA LOPES, 2008; RAJAGOPALAN, 2003; PENNYCOOK, 1998 etc.). Para tanto, o texto retoma, principalmente, as considerações acerca da linguagem e do papel do sujeito, para os estudos da LA, assim como para as teorias do Círculo. Com esta pesquisa, pretende-se contribuir para a concretização do estado da arte sobre a relação entre esses estudos, reforçando sua relevância para as pesquisas sobre linguagens, na perspectiva enunciativo-discursiva.

Palavras-chave: Linguística Aplicada; Círculo de Bakhtin; diálogos.

Abstract. This article, of bibliographic scope, aims to discuss, epistemologically and theoretically, the possible relations between the theories of the Bakhtin Circle (VOLOCHÍNOV, 1992[1929]; BAKHTIN, 1997 [1929/1963]; BAKHTIN, 2003[1979]) and those of Applied Linguistics (CELANI, 1992; KLEIMAN, 1998; MOITA LOPES, 2008; RAJAGOPALAN, 2003; PENNYCOOK, 1998 etc.). To this end, the text takes up, mainly, the considerations about the language and the role of the subject, for the studies of LA, as well as for the theories of the Circle. With this research, it is intended to contribute to the realization of the state of the art on the relationship between these studies, reinforcing its relevance to research on languages, in the enunciative-discursive perspective.

Keywords: Applied Linguistics; Bakhtin Circle; dialogues.

\footnotetext{
1 Mestra em Letras, pela Universidade Federal do Tocantins (UFT/PPGLetras/Porto Nacional). E-mail: marcondesbarrozo@hotmail.com

${ }^{2}$ Doutora em Linguística Aplicada, pela Universidade Estadual de Campinas (Unicamp). Professora adjunta da Universidade Federal do Tocantins (UFT), docente permanente do Programa de Pós-Graduação em Letras (PPGLetras/Porto Nacional) e do Programa de Pós-Graduação em Letras: Ensino de Língua e Literatura (PPGL/Araguaína). E-mail: angelafuza@uft.edu.br
} 


\section{Introdução}

Volochínov (1992 [1929]) compreende a linguagem como parte fundamental para a construção da realidade dialógica, uma vez que as permutas e reciprocidades discursivas entre mim e o outro, promovem a produção de enunciados e de enunciações, que são efetuadas em função da interpretação do ato discursivo, entre os sujeitos que se comunicam. Tendo em vista o caráter social na tratativa com a linguagem, exposta na Linguística Aplicada (doravante LA), torna-se plausível estabelecer elos com alguns dos estudos de Bakhtin (2003[1979]) e do Círculo, dado que, entender a linguagem é um acontecimento de cunho social e histórico. Dessa forma, ela é ideológica. Diante disso, percebe-se que esse estudioso (2003[1979]) dialoga de maneira fecunda com a linguística, apesar de, não realizar um julgamento a respeito da linguística e ainda admitir que as concepções, utilizadas por ela, são genuínas e justificáveis, compreendendo a exiguidade da linguística para empreender um estudo da comunicação verbal. Todas essas noções filosóficas, presentes em Bakhtin (2003[1979]), ganharam abrigo no espaço teórico da LA e fazem parte do seu eixo teórico epistemológico, conforme: 1) língua definida como objeto social e 2) sujeito engendrado como social e historicamente situado.

A partir disso, este estudo, de escopo bibliográfico, objetiva discutir, epistemológica e teoricamente, as possíveis relações entre as teorias do Círculo de Bakhtin (BAKHTIN, 2003[1979]; VOLOCHÍNOV, 1992[1929] etc.) e as da Linguística Aplicada (CELANI, 1992; KLEIMAN, 1998; MOITA LOPES, 2008; RAJAGOPALAN, 2003; PENNYCOOK, 1998 etc.). Para tanto, o texto retoma, principalmente, as considerações acerca da linguagem e do papel do sujeito, para os estudos da LA, assim como para as teorias do Círculo.

Este artigo, além do Resumo, Introdução e Conclusão, está organizado em mais três seções, assim distribuídas: (1) Breves considerações sobre Linguística Aplicada; (2) A linguagem segundo o viés dialógico; (3) Linguística Aplicada e os estudos do Círculo de Bakhtin: diálogos possíveis.

\section{Breves considerações sobre Linguística Aplicada}

Até os dias atuais, é possível afirmar que não existe um termo que defina satisfatoriamente a LA. Segundo Celani (1992), subsistem, até mesmo, dificuldades em aceitar a LA como uma área do conhecimento de foro próprio. Em função disso, é sabido que as definições iniciais da LA foram analisadas e definidas como parte menor da Linguística, ou 
seja, foi tida como uma subárea. Exemplificando, Crystal (2000) esclarece, no seu "Dicionário de Linguística e Fonética", ser a LA um ramo da linguística, sendo essencial a essa preocupação, a aplicação de teorias linguísticas, métodos e resultados, na elucidação de problemas linguísticos, que sejam originados de outras áreas e experiências. Nessa afirmação de Crystal (2000), depreende-se a LA como uma área restritiva, sendo dominada e bastante minguada pelas teorias linguísticas. Por outro prisma, Bohn (1988) discorda dessa análise, vislumbrando a LA, como uma disciplina independente, autônoma dos princípios da linguística teórica. Para esse autor, ela não é vista dentro de um processo em que determinadas convicções linguísticas são utilizadas na resolução de problema específico. Nesse sentido, a LA parte de um fato, de um problema concreto, de uma tomada de consciência dos problemas de ensino e da aprendizagem, por exemplo, passando a retratar de que forma os princípios linguísticos podem colaborar na solução do problema detectado.

A LA despontou, nos anos de 1950, e era encarada como parte da Linguística. Sua principal função estava focada nas aplicações do desenvolvimento de ensino de línguas, tendo como núcleo fundamental as línguas estrangeiras, visto que essas eram procedentes dos conceitos de linguagem estruturalistas e gerativistas. Nesse período, eram poucos os "linguistas aplicados", por isso, muitas atividades de LA eram executadas pelos "linguistas". Essa é uma das razões que faz a singularidade entre as duas ciências - Linguística e Linguista Aplicada serem tão complexas. Conseguintemente, é árduo imaginar uma junção entre as duas ciências, implicando, assim, uma carência de entendimento dessas teorias. O final dos anos 1980 e início dos anos 1990, foi o momento de relevantes discussões relacionadas à LA em que pesquisadores, como Celani (1992), Moita Lopes (1996) e Signorini (1998) deixam de entendêla como uma trivial aplicabilidade da linguística, passando a compreendê-la como área apartada, como campo de investigação autônoma.

A expressão "Linguística Aplicada" foi abraçada, há pouco tempo, após o incentivo dos estudos linguísticos, nas últimas décadas, por meio de debates estabelecidos pelos estudiosos dessa área. A princípio, ocorreram discussões por conta da precisão em determinar seu campo de trabalho e apontar sua meta de estudo com a Linguística. Em entendimento recente, a linguística foi definida como uma disciplina que pode abarcar diversas matérias, podendo ser utilizada para dar-lhes substâncias intelectuais. Essas matérias, consequentemente, podem ser compreendidas como elementos de outras disciplinas que não seja a Linguística.

A LA surgiu um pouco tardiamente, no que diz respeito ao momento em que se caracterizaram relevantes problemas no ensino de língua materna, no país, e foram os linguistas 
que preencheram os espaços de trabalho aplicado que, atualmente, a LA também pleiteia. Esses linguistas se colocavam à disposição para responder os questionamentos de professores que tinham dúvidas, pela frustração com alguns estudantes, que a democratização do ensino encaminhava para a escola, num efeito assemelhado a manada.

A interligação da LA com o ensino e a aprendizagem de línguas, conforme Celani (1992), expõe três conceitos epistemológicos, distintos: (a) a LA entendida como ensino e aprendizagem de línguas; (b) a LA interpretada como consumo, e não produção de teorias. Celani (1992) complementa sua ideia, asseverando que a LA: "seria um medidor entre descrições teóricas e atividades práticas diversas" (CELANI, 1992, p. 18); e, finalmente, sua terceira assertiva: c) a LA concebida numa função de espaço interdisciplinar, afirmando que: “área autônoma que constrói seus próprios princípios a partir da experimentação e de modificações na solução de problemas" (CELANI, 1992, p. 18), concluindo que existe um "ponto, então, onde o estudo da linguagem se intersecciona com outras disciplinas" (CELANI, 1992, p. 19). Logo, as ideias dessa estudiosa (1992) estão a explicitar acerca da LA, acreditando que sua matriz reside no ensino e na aprendizagem de línguas, numa situação efetiva de falantes e que ela permeia e alicerça os estudos de outras disciplinas. Ainda, de acordo com Celani (1992), em seu artigo “Transdiciplinaridade na Linguística Aplicada no Brasil”, entende-se que a LA é uma disciplina que articula muitos domínios do saber, dialogando permanentemente com diversos campos do conhecimento, que demonstram preocupação a respeito da linguagem. Celani (1992) complementa que:

Não há dúvida quanto ao caráter multi/pluri/interdisciplinar da Linguística Aplicada.
Os que nela militam a todo momento se dão conta de que estão entrando em domínios
outros que os de sua formação inicial, se dão conta de que precisam ir buscar
explicações para os fenômenos que investigam em outros domínios do saber que não
os da linguagem stricto-senso. Esse diálogo já faz parte da prática dos linguistas
aplicados (CELANI, 1992, p. 131).

Nesse sentido, Celani (1992) admite a característica multi/pluri/interdisciplinar da LA e testifica que os estudiosos devem buscar outros conhecimentos extra linguagem. Na década de 2000, aconteceu o fortalecimento da LA, apreciando-a como área de estudo dirigida às questões de uso da linguagem, na interação social, com a responsabilidade social de pensar em alternativas, que possibilitem melhorar o convívio entre os sujeitos, por intermédio da interação.

A LA determina-se como uma área própria de conhecimento. Seu terreno de estudo transita não somente sobre questões de sala de aula e de línguas, mas, preferencialmente, na relação com a linguagem em diversos contextos sociais, como: a linguagem utilizada no 
trabalho, na família, na mídia, por indivíduos socialmente expostos, entre outros (CAVALCANTE, 1986).

Segundo Rojo (2008), a atividade do linguista aplicado, na última década, tem o interesse voltado em entender e explicar problemas, com o intuito de criar ou aprimorar soluções para dificuldades, voltadas ao emprego da(s) linguagem(ens), dominados em sua contextualização, em sua relevância social, o que confere às soluções, condição de saberes adequado e proveitoso, para os partícipes de uma sociedade concreta. Dessa forma, "a orientação para o problema como abordagem dominante na LA substitui gradualmente a orientação para a teoria” (EVENSEN, 1998, p. 96).

Consoante às ideias de Kleiman (1998), os trabalhos desenvolvidos, no Brasil, como os artigos científicos e as teses enfocam a metodologia de construção de linguagem, quer considerando os textos dos estudantes ou observando a linguagem apresentada nos livros didáticos. Dessa forma, a LA começa e efetua o diálogo com outras áreas de conhecimento, dentre elas: a Psicologia, Sociologia, Antropologia etc. Assim, essas disciplinas, tomando para si a linguagem, iniciam e realizam estudos que anteriormente eram apenas investigados na Linguística. Ainda conforme Kleiman (2002), a LA, "tal qual desenvolvida no Brasil, situa-se definitivamente na tradição de pesquisa crítica, que não procura apenas descrever e explicar, mas também se posicionar em relação ao fato examinado e, ainda, oferecer encaminhamentos e soluções para os problemas estudados” (KLEIMAN, 2002, p. 189).

Outrossim, as pesquisas efetuadas, no Brasil, no campo da pesquisa crítica, não se limitam em descrever e explicar, mas tem por finalidade apresentar caminhos e soluções, no enfrentamento dos problemas existentes. Sendo assim, compreende-se que, na LA, "a questão política de proteção dos menos poderosos, dos mais pobres, dos menos escolarizados, tomando cuidado para que nossos resultados de pesquisa não possam ser utilizados para contribuir à desvalorização desses grupos" (KLEIMAN, 2002, p. 1998). Entende-se que a Linguística Aplicada deve equacionar igualitariamente as dificuldades enfrentadas pelos grupos e pessoas desprovidas de poder e escolaridade, tendo em vista cuidar para que essas pesquisas não venham concorrer para a depreciação desses indivíduos.

Moita Lopes (2008) comenta que uma tarefa fundamental da LA, no Brasil, é divulgar a sua natureza como área de investigação. A maior parte da pesquisa que se põe em foco são as questões relacionadas à aplicabilidade da linguagem em sala de aula, atingindo, consequentemente, aspectos relativos ao ensino e à aprendizagem de línguas e, também, interferindo na formação do professor. Assim, segundo Moita Lopes (1996), 
A LA tem como uma de suas tarefas no percurso de uma investigação mediar entre o conhecimento teórico advindo de várias disciplinas (exemplos, psicologia, educação linguística, etc.) e o problema de uso de linguagem que pretende investigar. O corpo de conhecimento vai depender das condições de relevância determinadas pelo problema a ser estudado (MOITA LOPES, 1996, p. 20-21).

As discussões mais recentes relacionadas às práticas de investigação em LA, comentadas por Moita Lopes (2006), pautam-se pela interdisciplinaridade. Sabe-se que Moita Lopes (1996) e Celani (1992), na década de 1990, destacavam a heterogeneidade das pesquisas em LA, tendo em vista que os linguistas aplicados já procuravam compreensão nas questões da utilização da linguagem, com o suporte de outras disciplinas.

Em 2001, Pennycook publica a obra "Critical Applied Linguistics: A Critical Introduction", que se constituiu como estrutura basilar e imprescindível da Linguística Aplicada Crítica (LAC). Desse momento em diante, processa-se uma alternância substancial no cerne dos problemas abordados pela LA, em razão da admissão de uma concepção crítica, impulsionando o surgimento da LAC. Esta é mais do que apenas uma dimensão crítica adicionada à Linguística Aplicada: “ela envolve um ceticismo constante, um constante questionamento dos pressupostos normativos da Linguística Aplicada" (PENNYCOOK, 2001, p. 10). Nessa perspectiva, Moita Lopes (2006) compartilha o ponto de vista de Pennycook (2001) e assegura que a LA deve trazer "para o centro de atenção, vidas marginalizadas do ponto de vista dos atravessamentos identitários de classe social, raça, etnia, gênero, sexualidade, nacionalidade" (MOITA LOPES, 2006, p. 25).

Em atenção à ideia de que a cultura e a aprendizagem de línguas acontecem incorporadas às relações de poder, o autor continua argumentando que o ensino de línguas "continua a trivializar-se, recusando-se a explorar aspectos políticos e culturais da aprendizagem de língua, ele estará mais vinculado à acomodação do que a qualquer noção de acesso ao poder" (PENNYCOOK, 1998, p. 27). Para o autor, na condição de professor ou pesquisador, "precisamos assumir posturas morais e críticas a fim de tentar melhorar e mudar um mundo estruturado na desigualdade" (PENNYCOOK, 1998, p. 39). Dessa maneira, uma das expressivas dificuldades da LAC seria conseguir meios viáveis para "compreender a relação entre os conceitos de sociedade, ideologia, capitalismo global, colonialismo, educação, gênero, racismo, sexualidade, classe e as interações de sala de aula" (PENNYCOOK, 2001, p. 5).

Dessa forma, é necessário transcender as teorias e os métodos de ensinar e começar a entreolhar e a respeitar os fatores circunjacentes, onde os sujeitos estão inseridos, como: cultura, religião e motivação. Conforme Miccoli (2010), as pesquisas e investigações feitas, no âmbito 
da LAC, são para oportunizar aos indivíduos participantes reflexões sobre as experiências vivenciadas, no decorrer de sua história, e também repensar as posturas adotadas em sala de aula, pois por meio da reflexão que as ações concretas podem se tornar mais conscientes e proveitosas. Logo, o conhecimento em relação à linguagem poderá ser ofertado à sociedade, mais satisfatoriamente, nas situações gerais da rotina social. Em consonância com Rajagopalan (2003), acreditar numa LAC é admitir ser exequível fazer a diferença. É confiar que o conhecimento em relação à linguagem pode e deve ser posto a serviço do bem-estar geral, da melhoria das condições sociais cotidianas (RAJAGOPALAN, 2003).

Na idealização desse entendimento, Rajagopalan (2003) aporta-se da ideia inicial para a reafirmação da LAC e justifica que essa deveria ter, no terreno da Linguística, uma ligação entre prática e ética, nos níveis do cidadão e do profissional. Para ele, a atividade profissional se inter-relaciona com a prática social, o profissional necessita adicionar, em sua atividade, diagnósticos, bem como intervenções referentes às práticas sociais. Assim, quando se fala em LAC, busca-se, primordialmente, reportar-se à linguística focada em questões práticas (RAJAGOPALAN, 2003).

\section{A linguagem segundo o viés dialógico}

Entender o dialogismo é analisar a ideia de que as comunicações são sempre efetuadas do locutor para o interlocutor, ou de si para si, e, ainda, por intermédio de outros ausentes, num processo constante e abrangente de interações sociais. Para Volochínov (1992 [1929]), a linguagem é influenciada e conduzida por fatores sociais e pelos interlocutores. Critica-se veementemente a ideia de a linguagem ser apenas exercida pelo indivíduo, em sua interioridade, deixando, neste contexto, de observar que a comunicação é uma relação puramente dialógica, que se constitui entre o eu e o outro, por intermédio da enunciação e do discurso. Ainda, segundo Bakhtin (2003 [1979]), o pensamento ideológico volta-se ao signo e, por isso, apreende um significado exterior a si mesmo. Os signos são decorrentes de uma conformidade entre sujeitos e seus convívios em sociedade, na qual estão inseridos. Constituem-se, dessa forma, pela sistematização social dos sujeitos, bem como por meio das circunstâncias procedimentais de interação.

O dialogismo que Bakhtin (2003[1979]) aborda é o primórdio característico da linguagem e a condição do sentido para o texto estabelecido, por meio da interação entre os sujeitos leitores, escritores e o próprio texto. Portanto, escrever e ler, por exemplo, para 
construir sentidos, são tipos de diálogos. Nessa interpretação, a teoria do Círculo de Bakhtin (1919-1974) está voltada para o estudo das peculiaridades da linguagem, a partir do aspecto dialógico. Em vista disso, o dialogismo é característica da linguagem e a condição de sentido discursivo, em que o enunciador, para compor um discurso, atravessa o discurso de outrem e compartilha com ele uma interação dinâmica e tensa (BAKHTIN, 2003 [1979]). A postura dialógica estabelece a condição interdiscursiva da linguagem e instaura uma permuta conversacional, proveniente da troca entre o eu e o tu, no processo de comunicação interativa, ou, ainda, uma manifestação pelo conflito oriundo da tensão básica na qual o tu, determina o que o eu, diz.

Em "Problemas da Poética de Dostoiévski", ao explicar que o seu objeto de estudo é o “discurso", Bakhtin (1997 [1929/1963]) o determina como sendo "a língua em sua integridade concreta e viva e não a língua como objeto específico da linguística" (BAKHTIN, 1997 [1929/1963], p. 181). Esse estudioso ainda destaca que, de acordo com essa perspectiva, "as relações dialógicas são absolutamente impossíveis, sem a relação, lógica e concreto-semântica, mas, são irredutíveis a estas, e têm especificidade própria” (BAKHTIN, 1997 [1929/1963], p. 184). Logo, o estudo da língua, como relação lógica, necessita de práticas enunciativas, com base nas relações dialógicas, apresentando caráter peremptório de racionalidade. Assim, percebe-se, neste aspecto, que as relações dialógicas adquirem conhecimentos, discursivamente na língua, enquanto fenômeno global concreto, nunca acabando as relações que lhes são congruentes. Logo, a concepção e assimilação entre relações dialógicas e lógicas resultam que a linguagem possui "vida" na comunicação dialógica, ou seja, na comunicação de sentidos, constituindo-se em atenção ao seu campo de existência.

Vale salientar que essas observações são retomadas no instante em que esse estudioso (1997 [1929/1963]) evidencia as relações dialógicas como relações de sentidos entre os enunciados, estando elas ou o sentido, inscritos em vozes discursivas, numa interação sóciohistórica. Dessa forma, pode-se dizer que o princípio dialógico carrega em seu propósito, uma abordagem da "não finalização" e do "vir-a-ser", caracterizando-se em razão disto, num princípio de "inconclusividade", da preservação, da heterogeneidade, da diferença e da alteridade (BAKHTIN, 1997 [1929/1963]). Compreende-se que a linguagem, consoante esse enfoque, concebe-se como uma reação-resposta em uma dada interação entre sujeitos e ficam perceptíveis às relações do locutor com os enunciados do outro. Assim sendo, é relevante e até necessário levar em consideração que o outro, no embate dialógico, não representa unicamente o interlocutor repentino, mas transcende e abarca a generalidade da comunicação num sentido 
lato. Em vista disso, as deliberações e definições de linguagem, pela ótica dialógica, denotam uma negação a qualquer forma vedada de tratar das questões da língua. Por isso, declarar a linguagem como discurso, em Bakhtin (2003 [1979]), é, sobretudo, reconhecer a sua "dialogicidade interna", porquanto, não é a forma composicional externa que vai determinar o teor dialógico.

Na perspectiva do Círculo de Bakhtin (1919-1974), a linguagem se constitui como uma espécie de diálogo, na medida em que todo enunciado aproveita vozes anteriores e pode, igualitariamente, ser empregada em discursos do porvir. Vale realçar que o conceito de dialogismo, em Bakhtin (2003[1979]), não se refere ao diálogo frente a frente entre indivíduos, mas sim, entre discursos, uma vez que, "o interlocutor só existe enquanto discurso" (FIORIN, 2006, p. 166). Faraco (1996) afirma que Bakhtin é o primeiro pensador contemporâneo a tratar e analisar a linguagem sem necessidade de separá-la da materialidade da vida social. Os pressupostos de Volochínov (1992[1929]) transcenderam a "Linguística Tradicional"3, num entendimento da construção da linguagem, segundo postulação dialógica, numa interação social e discursiva. Os estudiosos do Círculo, como Volochínov (1992 [1929]) são, inquestionavelmente, teóricos que contribuíram significativamente para os estudos relacionados ao diálogo, porquanto, ao ultrapassarem esses estudos, acreditaram em uma compreensão estrutural de diálogo. Eles também apresentam o diálogo como espaço de igualdades, litígios e assimetrias que manifestam os próprios aspectos da interação social. $\mathrm{O}$ diálogo não seria uma solicitação apenas de negociação e de mediação de conflitos, mas um espaço no qual essas igualdades e desigualdades podem ser acolhidas e repensadas de maneira que possam contribuir com o entendimento de uma realidade extensa, representada pela realidade social. Volochínov (1992[1929]) comenta que:

O diálogo, no sentido estrito do termo, não constitui, é claro, senão uma das formas é verdade que das mais importantes, da interação verbal. Mas pode-se compreender a palavra "diálogo" num sentido amplo, isto é, não apenas como a comunicação em voz alta, de pessoas colocadas face a face, mas toda comunicação verbal, de qualquer tipo que seja (VOLOCHÍNOV, 1992 [1929], p. 97).

\footnotetext{
${ }^{3}$ Volochínov (1992 [1929]) aborda orientações do pensamento filosófico linguístico que permitem compreender a linguagem de diferentes ângulos, a saber: Subjetivismo Idealista, Objetivismo Abstrato e Concepção Dialógica de Linguagem. As duas primeiras orientações não alcançam a essência da realidade linguística, por considerarem, de modo geral, que a língua é um sistema imóvel e acabado, de signos e regras, sem a interferência de fatores sociais nesse sistema.
} 
Conclui-se que a linguagem, sob esse aspecto, constitui-se como uma reação-resposta mediante uma interação verbal anterior, entre locutor e interlocutor, por intermédio dos enunciados do outro. Assim, a linguagem, indubitavelmente, é uma atividade instituída em um processo concreto, no qual o signo se constrói ideologicamente e dialogicamente.

\section{Linguística Aplicada e os estudos do círculo de Bakhtin: diálogos possíveis}

Nas considerações acerca da LA, é imperativo admitir a importância que a linguagem exerce sobre os indivíduos, uma vez que ela se expressa sobre o mundo real e mental, metodizando e estabelecendo conceitos e princípios, criando condições de compreensão para as esferas e situações mais distintas da sociedade.

A linguagem disponibiliza o entendimento entre as pessoas, viabiliza a participação indispensável dos indivíduos, por intermédio da interação verbal-social. Em razão da premente necessidade da linguagem, nas comunicações humanas, há muito tempo, os estudiosos têm se dedicado ao seu estudo. Para Volochínov (1992[1929]), a linguagem é um acontecimento de cunho social e histórico, pois a medula da análise linguística é o enunciado, ou seja, são os componentes linguísticos que são gerados e elaborados nos distintos contextos sociais por indivíduos que necessitam comunicar-se. O indivíduo se constitui em razão do meio do qual faz parte, ouvindo o discurso do outro, muitas vezes, sem se dar conta das falas proferidas. Logo, essas palavras passam por um processo amalgâmico e de regressão, numa fusão das palavras do eu com as palavras do outro e de todos.

Volochínov (1992[1929]) têm a linguagem como um campo de controvérsia, perpassado pela auréola do poder. Para o autor, o signo é materialmente constituído e sua produção dialógica se dá no contexto de todos os signos sociais. Neste cenário, o sujeito é também constituído e constitui seu enunciado, carregado de ecos de outros discursos. Brandão (1995) corrobora dizendo que Volochínov (1992[1929]) prioriza a enunciação como a própria realidade da linguagem: "A matéria linguística é apenas uma parte do enunciado; existe também outra parte não-verbal, que corresponde ao contexto da comunicação" (BRANDÃO, 1995, p. 9). Diante disso, ratifica-se que os pressupostos do Círculo dialogam de maneira fecunda com a linguística. Apesar de não realizarem um julgamento acerca dela e ainda acreditarem que as concepções utilizadas por ela são genuínas e justificáveis, compreendem a exiguidade da linguística, para realizar um estudo da comunicação verbal. Tendo em vista que os sujeitos são históricos e que há uma unidade dialética entre o mundo da cognição e o mundo da vida, esse 
espaço de estudo busca estudar problemas linguísticos, que são valorosos socialmente, como: a interação, as práticas de linguagem, entendendo que a linguagem é uma dialogização de axiologias, aumentando seu campo de análise linguística, para as relações sociais em todos os contextos.

Ao tratar do viés dialógico, social da linguagem, é possível retomar a noção de que, apesar da linguagem estar no centro da LA, seu estudo não é indispensavelmente dominado pela Linguística (CELANI, 1992). Seguindo seu raciocínio, a pesquisadora reitera que, se for efetuada uma relação da LA com distintas disciplinas, as inter-relações continuam. Logo, a LA

Estaria provavelmente no centro do gráfico, com setas bidirecionais dela partindo para um número aberto de disciplinas relacionadas com a linguagem, entre as quais estaria a Linguística, em pé de igualdade, conforme a situação, com a Psicologia, a Antropologia, a Sociologia, a Pedagogia ou a tradução (CELANI, 1992 p. 21).

Nesse sentido, a LA se encontra numa situação igualitária com a Linguística. Entretanto, ela estaria num local de centralidade em relação à Linguística. Assim, entende-se que a LA estaria numa função principal com respeito às outras disciplinas que estão inevitavelmente relacionadas à linguagem. Entende-se que na interação entre indivíduos, por meio da linguagem, ocorre a identidade linguística, que se constrói na interação comunicativa e que está correlacionada e depende de fatores diversos, como: atitudes afetivas e cognitivas, as quais se concretizam por meio das atividades linguísticas. São esses fatores que consentem os sujeitos expressarem a sua identidade e sua avaliação, com respeito à própria forma de falar e a fala dos outros.

No entender de Hoffnagel (2010), deve-se optar pela confluência com a perspectiva não essencialista, numa percepção de que a identidade é uma: "realização interacional, negociada e alcançada em eventos comuns, como traços constitutivos de encontros sociais" (HOFFNAGEL, 2010, p. 64). Busca-se, portanto, conhecer como a LA contribui na formação desses sujeitos, especialmente, no âmbito do ensino.

Conforme Moita Lopes: "Os significados com que operamos inclusive aqueles sobre quem somos, não são dados no mundo, não existem antes da linguagem, mas, são produzidos nas práticas discursivas em que atuamos" (MOITA LOPES, 2002, p. 33). Dessa forma, a linguagem edifica o mundo e participa da elaboração de nossa identidade. A linguagem é responsável pela nossa construção e reconstrução, com significados expostos por intermédio do discurso. Nesse processo contínuo de construção e reconstrução, a linguagem e o contexto devem ser permanentemente avaliados, em função de que o contexto e a linguagem permeiam 
as comunicações dos sujeitos falantes. Dessa maneira, averígua-se, com base nos estudos e nos procedimentos, que o conhecimento não se encontra presente unicamente na Linguística.

Bakhtin (2003 [1979]) argumenta em suas teorias, a concepção da linguagem como reflexo social, e fortalece, doravante, princípios essenciais para o estudo do discurso: a de polifonia e a de dialogia, que dizem respeito, de modo geral, à multiplicidade de vozes presentes no discurso e às relações que entre elas se estabelecem compulsoriamente. Para esse estudioso (2003 [1979]), todas as manifestações de vozes explícita ou implicitamente dão forma ao discurso, além de retratarem as intenções do enunciador, reverberam, precipuamente, os sentidos e os valores que estruturam a sociedade. Outra consideração importante, defendida por Bakhtin (2003 [1979], p. 41]), é que "a palavra penetra literalmente em todas as relações entre indivíduos", e complementa esta afirmação ao mencionar que "as palavras são tecidas a partir de uma multidão de fios ideológicos e servem de trama a todas as relações sociais em todos os domínios".

É possível afirmar que essas noções filosóficas, encontradas nos estudos do Círculo, aqui expostas, ganharam abrigo no espaço teórico da LA e fazem parte do seu eixo teóricoepistemológico: 1) língua definida como objeto social; 2) sujeito engendrado como social e historicamente situado. Assim, tanto nos pressupostos do Círculo, quanto nas teorias de LA, os sujeitos são vistos históricos, apresentando unidade dialética entre o mundo da cognição e o mundo da vida, sendo possível tratar da interação social e das diferentes práticas de linguagens, entendendo que a linguagem é uma dialogização de axiologias e acresce seu espaço com a análise linguística, nas relações sociais e em todos os contextos.

\section{Conclusão}

Ao longo desse trabalho, foi possível conhecer um pouco acerca da LA e averiguar que existe, desde o século XIV, a necessidade de uma definição para ela. Com o passar do tempo, ela foi consolidada em razão da enorme variedade das pesquisas, cimentando, dessa maneira, sua condição autônoma. Alicerçada, desenvolveram-se e ampliaram-se as possibilidades de estudo, em especial, no entendimento de que a linguagem é um produto que advém das práticas discursivas sociais. Outras perspectivas e dimensões cingiram-se as novas pesquisas, alargando os espaços da LA no arfam de compreendê-la e enriquecê-la, tendo em vista o campo extensivo, em razão de sua complexidade, quando delineia as junções entre a LA e os contextos da interação verbal, do enunciado e dos ambientes sócio-históricos. 
Com base nos estudos aqui elencados, entende-se que a linguagem edifica o mundo e participa da elaboração da identidade dos sujeitos, que se baseia na própria identidade da linguagem utilizada pelos falantes, especialmente, na língua materna. Sabe-se que a linguagem é o sumário significativo da identidade. As escolhas enunciativas feitas pelos indivíduos são jungidas às muitas dimensões constitutivas da identidade social e às diversas atitudes sociais que o falante adota na comunidade, porém, o que determina a escolha de uma determinada diversidade, é a situação real de comunicação.

A partir dos pressupostos teóricos e metodológicos de natureza espontânea, moldável, elástica e híbrida, adotados no campo da LA, as pesquisas e suas implicações de forma prática, envolvem para uma conscientização de que a LA pode contribuir substancialmente para o ensino e a aprendizagem, atendendo as aspirações e as necessidades da classe estudantil e professores, pesquisadores e teóricos. Nesse diapasão, a LA vai ocupando os espaços líquidos, tornando-se, cada vez mais, atual. Assim sendo, vale enfatizar a relevância na demanda pela interface entre os estudos da LA, os pressupostos do Círculo de Bakhtin e outros teóricos, quanto aos aspectos do estudo sobre língua/linguagem.

Conclui-se, portanto, que a linguagem é responsável pela construção e reconstrução social das práticas sociais, com significados expostos por intermédio do discurso. Nesse processo contínuo de construção e reconstrução, a linguagem e o contexto devem ser permanentemente avaliados, em função de que o contexto e a linguagem permeiam as comunicações dos sujeitos falantes. Logo, evidencia-se a possibilidade de diálogos entre os estudos da LA e os pressupostos do Círculo de Bakhtin visto que, de modo geral, ponderam que os sujeitos são históricos e que há uma unidade dialética entre o mundo individual/social e o mundo da vida, por isso, admite-se que a interação e as práticas de linguagem representam uma dialogização de axiologias, aumentando seu espaço de análise linguística, nas relações sociais.

Nos limites a que este texto se restringiu, espera-se ter contribuído para novas reflexões sobre os elos possíveis entre os estudos da Linguística Aplicada e os pressupostos de Bakhtin, sendo ainda possível a ampliação dessas discussões, tendo em vista outros textos do Círculo.

\section{Referências}

BAKHTIN, M. M. Os gêneros do discurso. In: BAKHTIN, M. M. Estética da criação verbal. Tradução do russo por Paulo Bezerra. 4.ed. São Paulo: Martins Fontes, 2003 [1979], p. 261306. 
BAKHTIN, M. Problemas da poética de Dostoiévski. 2. ed. rev. Rio de Janeiro: Forense Universitária, 1997 [1929/1963].

BOHN H. I. Linguística Aplicada. In: BOHN, H. I.; VANDRESEN, P. (Org.) Tópicos de linguística aplicada: o ensino de línguas estrangeiras. Florianópolis: Ed. da UFSC, 1988, p. 11 39.

BRANDÃO, H. H. N. Introdução à análise do discurso. 4. ed. Campinas: UNICAMP, 1995.

CAVALCANTI, M. A propósito de linguística aplicada. Trabalhos em linguística aplicada, v. 7, n. 2, p. 5-12, 1986.

CELANI, M. A. A. Afinal, o que é Linguística Aplicada. In: ZANOTTO, M. S. \& CELANI, M. A. A. (Org.). Linguística Aplicada, da aplicação da linguística a linguística transdisciplinar. São Paulo: EDUC, 1992, p.15-23.

CRYSTAL D. Dicionário de Linguística e Fonética. Editora: Jorge Zahar Editor, 2000.

EVENSEN, L. S. A linguística aplicada a partir de um arcabouço com princípios caracterizadores de disciplinas e transdisciplinas. In: SIGNORINI, I. \& CAVALCANTI, M. C. (Org.). Linguística aplicada e transdiciplinaridade. Campinas: Mercado de Letras, 1998, pp. 81-98.

FARACO, C. A.; TEZZA, C.; CASTRO, G. (Orgs.). Diálogos com Bakhtin. Paraná: Editora da Universidade Federal do Paraná, 1996.

FIORIN, J. L. O dialogismo. In: FIORIN, J. L. Introdução ao Pensamento de Bakhtin. São Paulo: Ática, 2006, p. 18-59.

HOFFNAGEL, J. C. A narrativa como lugar da expressão da identidade social. In: HOFFNAGEL, J. C. Temas em antropologia e linguística. Recife: Bagaço, 2010, p. 63-79.

KLEIMAN, A. B. O estatuto disciplinar da linguística aplicada: O traçado de um percurso. Um rumo para o debate. In: SIGNORINI, I. \& CAVALCANTI, M. C. (Org.) In: Linguística aplicada e transdiciplinaridade. Campinas: Mercado de Letras, 1998, p. 51-77.

KLEIMAN, A. B. Interface de questões éticas e metodológicas na pesquisa em Linguística Aplicada, In: da Silva, Denise E. G. \& Vieira, Josênia A (Orgs). Análise do Discurso Percursos Teóricos e Metodológicos. Brasília: UnB, Editora Oficial do Instituto de Letras, Editora Plano, 2002, p. 187-202.

MICCOLI, L. S. Ensino e aprendizagem de Inglês: experiências, desafios e possibilidades. Campinas: Pontes Editores, 2010.

MOITA LOPES, L. P. Uma linguística aplicada mestiça e ideológica. In: MOITA LOPES, L. P. (Org.). Por uma Linguística Aplicada Indisciplinar. 2 ed. São Paulo: Parábola Editorial, 2008, p. 13-42.

MOITA LOPES, L. P. Por uma linguística aplicada indisciplinar. São Paulo: Parábola, 2006. 
MOITA LOPES, L. P. Afinal, o que é linguística aplicada. In: Moita Lopes, L. P. Oficina de linguística aplicada. Campinas: Mercado de Letras, 1996, p. 17-25.

MOITA LOPES, L. P. Narrativa como processo de construção da identidade social de raça. In: MOITA LOPES, L. P. Identidades fragmentadas: a construção discursiva de raça, gênero e sexualidade em sala de aula. Campinas, SP: Mercado das Letras, 2002, p. 57-81.

PENNYCOOK, A. A linguística aplicada dos anos 90: em defesa de uma abordagem crítica. In: SIGNORINI, I.; CAVALCANTI, M. C. (org.). Linguística aplicada e transdisciplinaridade. Campinas: Mercado de Letras, 1998, p. 23-49.

PENNYCOOK, A. A Critical Applied Linguistics: a critical introduction. Mahwah, NJ: Lawrence Erlbaum Associates, 2001.

RAJAGOPALAN, K. Por uma linguística crítica: linguagem, identidade e a questão ética. São Paulo: Parábola Editorial, 2003.

ROJO, R. Fazer linguística aplicada em perspectiva sócio-histórica. In: MOITA LOPES, L. P. (Org.). Por uma Linguística Aplicada Indisciplinar. 2 ed. São Paulo: Parábola Editorial, 2008, p. 253-275.

SIGNORINI, I.; CAVALCANTI, M. $\quad$ C. Linguística Aplicada e transdisciplinariedade. Campinas: Mercado de Letras, 1998.

VOLOCHÍNOV. Marxismo e Filosofia da Linguagem. Tradução de Michel Lahud e Yara Frateschi Vieira. 6. ed. São Paulo: Hucitec, 1992 [1929]. 